\title{
Alterations on the growth and ultrastructure of Leishmania chagasi induced by squalene synthase inhibitors
}

\author{
Ana Claudia Granthon ${ }^{\mathrm{a}}$, Marina V. Braga ${ }^{\mathrm{b}}$, Juliany C.F. Rodrigues ${ }^{\mathrm{a}}$, Simon Cammerer ${ }^{\mathrm{c}}$, \\ Silvia Orenes Lorente ${ }^{\mathrm{c}}$, Ian H. Gilbert ${ }^{\mathrm{c}}$, Julio A. Urbina ${ }^{\mathrm{d}}$, Wanderley de Souza ${ }^{\mathrm{a}, *}$ \\ ${ }^{a}$ Laboratório de Ultraestrutura Celular Hertha Meyer, Instituto de Biofísica Carlos Chagas Filho, Universidade Federal do Rio de Janeiro, CCS, \\ Bloco G-subsolo, Ilha do Fundão, CEP 21949-900 Rio de Janeiro, RJ, Brazil \\ ${ }^{\mathrm{b}}$ Depto. de Biologia, Instituto Oswaldo Cruz, Fundação Oswaldo Cruz, Rio de Janeiro, RJ, Brazil \\ ${ }^{\mathrm{c}}$ Welsh School of Pharmacy, Cardiff University, King Edward VII Avenue, Cardiff, CF10 3XF, UK \\ ${ }^{\mathrm{d}}$ Laboratorio de Química Biológica, Centro de Biofísica y Bioquímica, Instituto Venezolano de Investigaciones Científicas, Venezuela
}

Received 21 October 2006; received in revised form 13 December 2006; accepted 24 December 2006

\begin{abstract}
Leishmaniasis is an important disease in widely dispersed regions of the world. In South America, visceral leishmaniasis (VL) is mainly caused by Leishmania chagasi. The morbidity associated with the infection is high, and death may occur in some untreated patients. Treatment has been based upon pentavalent antimonial drugs for more than half a century and problems, including development of resistance to antimonials and lack of efficacy against VL/HIV co-infections, have emphasized the need for new drugs. Squalene synthase (SQS) is an essential enzyme for the biosynthesis of protozoal sterol molecules. In this work, nineteen synthetic quinuclidines, potentially inhibitors of SQS, were tested against promastigote forms of $L$. chagasi and the $\mathrm{IC}_{50}$ values of the compounds were determined. The most active compounds had $\mathrm{IC}_{50}$ values of around $30 \mathrm{nM}$ and induced complete growth arrest and cell lysis at sub-micromolar concentrations. We analyzed the morphological structure of the parasites treated with these compounds by transmission electron microscopy of thin sections. Treated parasites showed significant ultrastructural changes, which varied from discrete alterations to total destruction of the cells, depending on the drug concentration and the time of incubation. One important change observed was a typical swelling of the unique and highly branched mitochondrion, where the inner membrane lost its organization. There was an increase in the number of autophagosomal structures. Changes in the organization of the nuclear chromatin and alterations in the flagellar pocket and flagellar membrane were also observed.

Crown Copyright (C) 2007 Published by Elsevier B.V. All rights reserved.
\end{abstract}

Keywords: Leishmania; Squalene synthase; Sterol biosynthesis inhibitors; Ergosterol; Chemotherapy; Ultrastructure

\section{Introduction}

Leishmaniasis is a disease caused by a number of species of protozoa of the genus Leishmania. There are four major clinical types of this infection: cutaneous, diffuse cutaneous, mucocutaneous and visceral (WHO,

\footnotetext{
* Corresponding author. Tel. +55 212260 2364; fax: +552122602364.

E-mail address: wsouza@biof.ufrj.br (W. de Souza).
}

2002). Leishmania chagasi, Leishmania infantum and Leishmania donovani are the causative agents of visceral leishmaniasis (VL) or Kala-azar in humans. In South America, VL is mainly caused by L. chagasi and transmitted by sandfly bites. The disease, affecting both children and adults, typically presents fever, hepatosplenomegaly and pancytopenia. Of all forms of leishmaniasis, VL is the most severe form, and if untreated is almost always fatal (Sundar, 2001; Rosenthal and Marty, 2003). 
Domestic dogs play an important role in VL maintenance by serving as reservoirs of the parasite. Both asymptomatic and symptomatic infected dogs are infective to the sandfly vectors (Molina et al., 1994). Control of canine VL remains difficult and a serious problem mostly because there is no reliable and effective treatment for the infected dogs.

The first-line therapies against leishmaniasis are the two pentavalent antimonial compounds, sodium stibogluconate (Pentostam ${ }^{\mathbb{R}}$ ) and meglumine antimoniate (Glucantime ${ }^{\circledR}$ ). They have a number of drawbacks: they require parenteral administration; they have significant toxic side effects; and widespread resistance to them is reported mainly in India, Kenya and Sudan (Rakotomanga et al., 2004). The two second-line agents, pentamidine isethionate and amphotericin B desoxycholate, are also administered parenterally and are more toxic. Liposomal amphotericin B is effective and safe, but the cost of treatment is very high (Bhattacharya et al., 2004).

Miltefosine (hexadecylphosphocholine) inhibits phospholipids and sterol biosynthesis of trypanosomatids (Lira et al., 2001; Urbina, 2006) and is effective in vivo against Leishmania, even by the oral route (Kuhlencord et al., 1992; Sinderman et al., 2004). However, its long half-life (approximately $150 \mathrm{~h}$ ) and teratogenic potential are important drawbracks, as development of drug resistance may eventually lead to a premature end of using this very important drug (Sundar, 2001; Ganguly, 2002).

Sterol biosynthesis inhibitors (SBIs) have been found to be particularly useful, as endogenous sterols are essential for survival of the trypanosomatid parasites. These compounds are in most cases orally active and have broad activity spectrum and very low toxicity (Urbina, 1999). The SBIs act by depleting essential and specific membrane components and/or inducing the accumulation of toxic intermediates or lateral products of the biosynthetic pathway (Contreras et al., 1997). A number of different enzymes in the sterol biosynthetic pathway have been investigated as anti-trypanosomatid drug targets, including: HMGCoA reductase, farnesyl-pyrophosphate synthase, squalene epoxidase, $14 \alpha$-demethylase and sterol 24-methyltransferase (Lazardi et al., 1990; Vannier-Santos et al., 1995; Urbina, 1997; Contreras et al., 1997; Rodrigues et al., 2002, 2005; Urbina et al., 2002, 2004; Roberts et al., 2003; Braga et al., 2004). Inhibition of some of these enzymes led to compounds which have potent antiparasitic activity. Also, where investigated, simultaneous inhibition of several of the enzymes led to synergistic effect.
Squalene synthase (SQS), an essential enzyme of the sterol biosynthesis pathway, catalyses an unusual head to head reductive dimerization of two molecules of farnesyl-pyrophosphate (FPP) in a two-step reaction to form squalene. This is the first commited step in sterol biosynthesis; a blockage at this level of the pathway should not affect the production of other essential isoprenoids and the accumulated isoprenoid intermediates (FPP and precursors) can be readily metabolized and excreted (Barrett-Bee and Ryder, 1992; Oehlschlager and Czyzewska, 1992; Urbina et al., 2002).

Until now, few studies have been published directly concerned with $L$. chagasi. The lack of orally administered effective drugs for VL has prompted the search for new potential therapeutic agents for both humans and domestic animals such as dogs. Sterol biosynthesis seems to be an excellent chemotherapeutic target for trypanosomatids. In this work, we describe the effect of nineteen specific inhibitors of SQS on growth and ultrastructure of $L$. chagasi promastigotes.

\section{Materials and methods}

\subsection{Parasites and growth conditions}

The MHOM/BR/2000/MS501 (Odinei) strain of L. chagasi isolated from a patient with visceral leishmaniasis in Bodoquena, Mato Grosso do Sul, Brazil, in March of 1999, was used in the present study. The parasites were maintained by serial passage in Gold hamsters. Amastigotes were isolated from hamster spleens and allowed to convert to promastigotes and multiply in M199 medium supplemented with $10 \%$ fetal bovine serum (Laborclin, Brazil) at $26{ }^{\circ} \mathrm{C}$.

\subsection{Drugs and growth curves}

Nineteen compounds were tested: BPQ-OH (3(biphenyl-4-yl)-3-hydroxyquinuclidine, 1), compounds 2-16, ER-27856, ER-119884 and E5700, see Fig. 1. Compounds 1-16 were prepared at Cardiff. Preparation of 1-4 has been reported (Lorente et al., 2005). Details of preparation of 5-16 will be reported elsewhere. ER27856, ER-119884 and E5700 were provided by Tsukuba Research Laboratories, Eisai Company Ltd., Japan. The compounds were added as dimethyl sulfoxide (DMSO) solutions, the final DMSO concentration of the stock never exceeded $1 \%(\mathrm{v} / \mathrm{v})$ and had no effects on the proliferation of parasites.

The cultures were initiated with a cell density of $2 \times 10^{6}$ cells $/ \mathrm{ml}$ and the drugs were added $24 \mathrm{~h}$ later. The cell density was measured by direct counting on a 


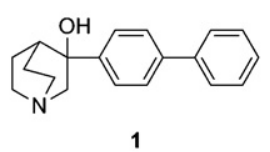

1<smiles>Oc1ccc(-c2ccc(C3=CN4CCC3C4)cc2)cc1</smiles><smiles>C1=C(c2ccc(-c3ccccc3)cc2)C2CCN1C2</smiles>

2

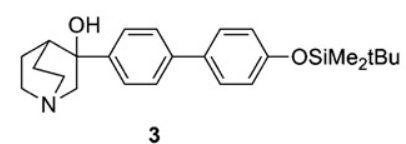<smiles>O=Cc1ccc(C=C2CN3CCC2C3)cc1</smiles><smiles>C(=C1CN2CCC1C2)c1ccc(C2OCCO2)cc1</smiles>

11<smiles>c1ccc(CC2CN3CCC2C3)cc1</smiles>

12<smiles>C(=C1CN2CCC1C2)c1ccc(-c2ccccc2)cc1</smiles>

9<smiles>C(=C1/CN2CCC1C2)\c1ccc(C2OCCO2)cc1</smiles><smiles>c1ccc2cc(CC3CN4CCC3C4)ccc2c1</smiles>

13<smiles>O=C(O)c1ccc(C#CC2(O)CN3CCC2C3)cc1</smiles>

16<smiles>COC1CN(c2ccc(C#CC3(O)CN4CCC3CC4)c(Cc3ccccc3)n2)CC1O</smiles>

E5700

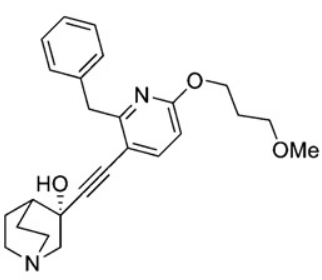

ER119884

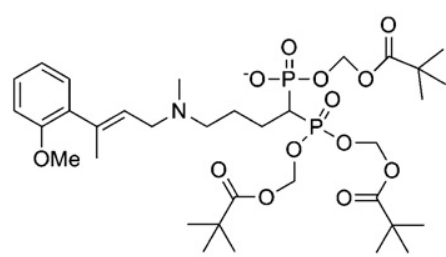

ER27856<smiles>c1ccc(-c2ccc(CC3CN4CCC3C4)cc2)cc1</smiles>

Fig. 1. Chemical structures of the compounds used in this study.

haemocytometer. The cells were counted daily up to $96 \mathrm{~h}$ of treatment (five days culture). The dye exclusion test was also done to verify the cell viability, using erytrosin B.

The $\mathrm{IC}_{50}$ (minimum concentration needed to inhibit $50 \%$ of growth) was calculated using the following formula (Martin et al., 2001):

$I=\frac{I_{\max } \times C}{\mathrm{IC}_{50}+C}$

where $I=$ percentage of inhibition, $I_{\max }=100 \%$ and $C=$ concentration. For this purpose, the parasites were counted on the fifth day of culture ( $96 \mathrm{~h}$ of treatment).

\subsection{Transmission electron microscopy (TEM)}

Control and treated parasites were fixed with a solution containing $2.5 \%$ glutaraldehyde and $4 \%$ paraformaldehyde in $0.1 \mathrm{M}$ cacodylate buffer, $\mathrm{pH}$ 7.2 , post-fixed with $1 \%$ osmium tetroxide $\left(\mathrm{OsO}_{4}\right)$ and $0.8 \%$ potassium ferrocyanide in $0.1 \mathrm{M}$ cacodylate buffer, dehydrated in graded acetone and embedded in Epon. Ultra-thin sections were stained with uranyl acetate and lead citrate and observed in a ZEISS 
Table 1

$\mathrm{IC}_{50}$ for several inhibitors of squalene synthase tested against promastigote forms of Leishmania chagasi

\begin{tabular}{ll}
\hline Compounds & $\mathrm{IC}_{50}(\mu \mathrm{M})$ \\
\hline $\mathbf{1}(\mathrm{BPQ}-\mathrm{OH})$ & $0.03 \pm 0.01$ \\
$\mathbf{2}$ & $0.02 \pm 0.01$ \\
$\mathbf{3}$ & $0.06 \pm 0.02$ \\
$\mathbf{4}$ & $0.02 \pm 0.03$ \\
$\mathbf{5}$ & No inhibition \\
$\mathbf{6}$ & $4.88 \pm 0.26$ \\
$\mathbf{7}$ & $6.69 \pm 1.90$ \\
$\mathbf{8}$ & $2.23 \pm 0.68$ \\
$\mathbf{9}$ & No inhibition \\
$\mathbf{1 0}$ & $24.0 \pm 7.00$ \\
$\mathbf{1 1}$ & $10.1 \pm 2.00$ \\
$\mathbf{1 2}$ & $24.0 \pm 5.00$ \\
$\mathbf{1 3}$ & $0.92 \pm 0.30$ \\
$\mathbf{1 4}$ & $0.06 \pm 0.13$ \\
$\mathbf{1 5}$ & $0.18 \pm 0.10$ \\
$\mathbf{1 6}$ & $1.50 \pm 0.35$ \\
ER27856 & $3.8 \pm 1.60$ \\
ER 119884 & $0.06 \pm 0.01$ \\
E5700 & $0.07 \pm 0.02$
\end{tabular}

EM900 and in a JEOL 1200EX transmission electron microscope.

\section{Results}

Table 1 shows the $\mathrm{IC}_{50}$ for all nineteen compounds tested. Most of them inhibited promastigotes growth at concentrations $\leq 5 \mu \mathrm{M}$. Compounds 1-4, ER-119884 and $\mathrm{E} 5700$ gave the lowest $\mathrm{IC}_{50}$ values (most active compounds) (Table 1). It is important to point out that for several compounds $\mathrm{IC}_{50}$ values in the nanomolar range were obtained (Figs. 2 and 3). For some compounds, complete growth arrest was observed after just $24 \mathrm{~h}$ of contact at sub-micromolar concentrations and Compounds 1-4 induced cell lysis at $0.5 \mu \mathrm{M}$ and $72 \mathrm{~h}$ of treatment (Figs. 3 and 4). These effects were observed at a ten-fold lower concentration when the

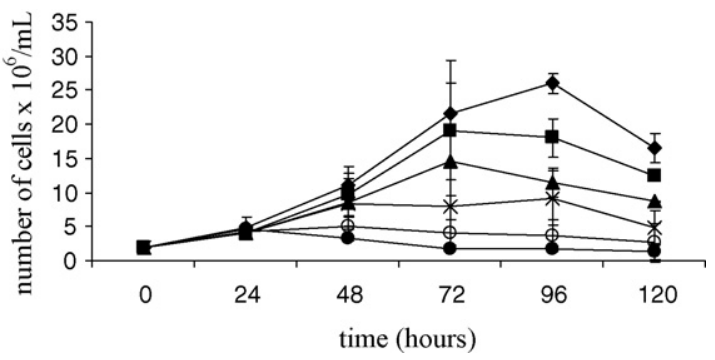

Fig. 2. Growth curve of $L$. chagasi promastigotes treated with ER119884. The compounds were added after $24 \mathrm{~h}$ of cultivation:

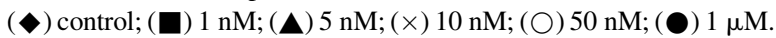

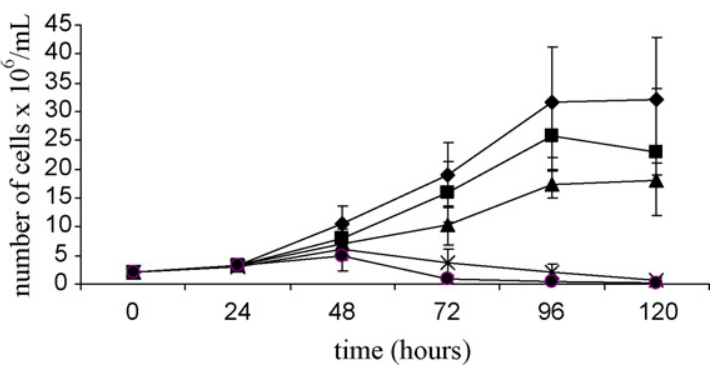

Fig. 3. Growth curve of $L$. chagasi promastigotes treated with compound $1(\mathrm{BPQ}-\mathrm{OH})$. The compound was added after $24 \mathrm{~h}$ of cultivation: $(\diamond)$ control; $(\boldsymbol{\square}) 0.01 \mu \mathrm{M} ;(\boldsymbol{\Delta}) 0.1 \mu \mathrm{M} ;(\times) 0.5 \mu \mathrm{M}$; $1 \mu \mathrm{M}$.

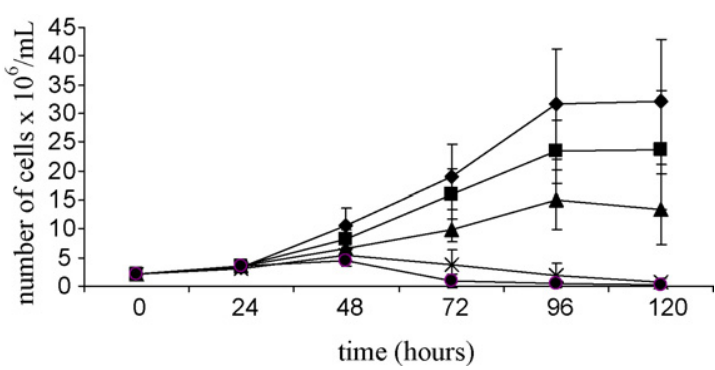

Fig. 4. Growth curve of $L$. chagasi promastigotes treated with compound 2. The compound was added after $24 \mathrm{~h}$ of cultivation: control; (c) $0.01 \mu \mathrm{M}$; ( $\mathbf{\Delta}) 0.1 \mu \mathrm{M}$; (×) $0.5 \mu \mathrm{M}$; (○) $1 \mu \mathrm{M}$.

cells were treated with ER-119884 (Fig. 2) and E5700. On the other hand, the $\mathrm{IC}_{50}$ value for ER27856, a prodrug of a bisphosphonate-based SQS inhibitor (Fig. 1), was $3.8 \mu \mathrm{M}$.

Direct observation of treated parasites by light microscopy showed that the cells became rounded and lost their motility. The dye exclusion test was also done to verify the cell viability. A marked reduction in cell viability was observed after $72 \mathrm{~h}$ of drug treatment (Fig. 5).

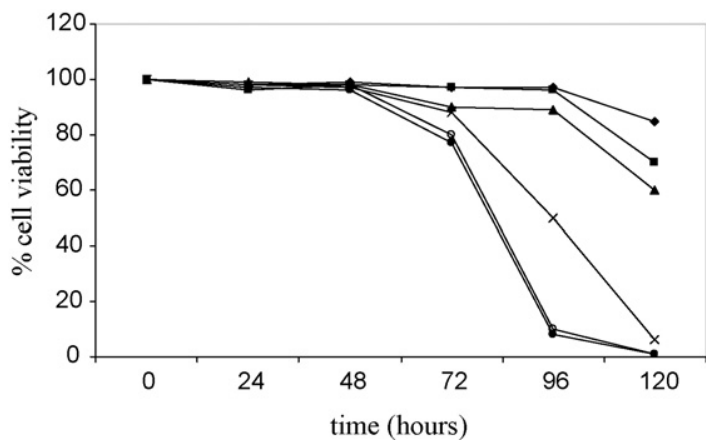

Fig. 5. Cell viability after treatment with ER-119884. The compound was added after 24 hof cultivation: $(\diamond)$ control; $(\diamond)$ : $1 \mathrm{nM}$; $5 \mathrm{nM} ;(\times) 10 \mathrm{nM} ;(\bigcirc) 50 \mathrm{nM} ;(\bullet) 1 \mu \mathrm{M}$. 

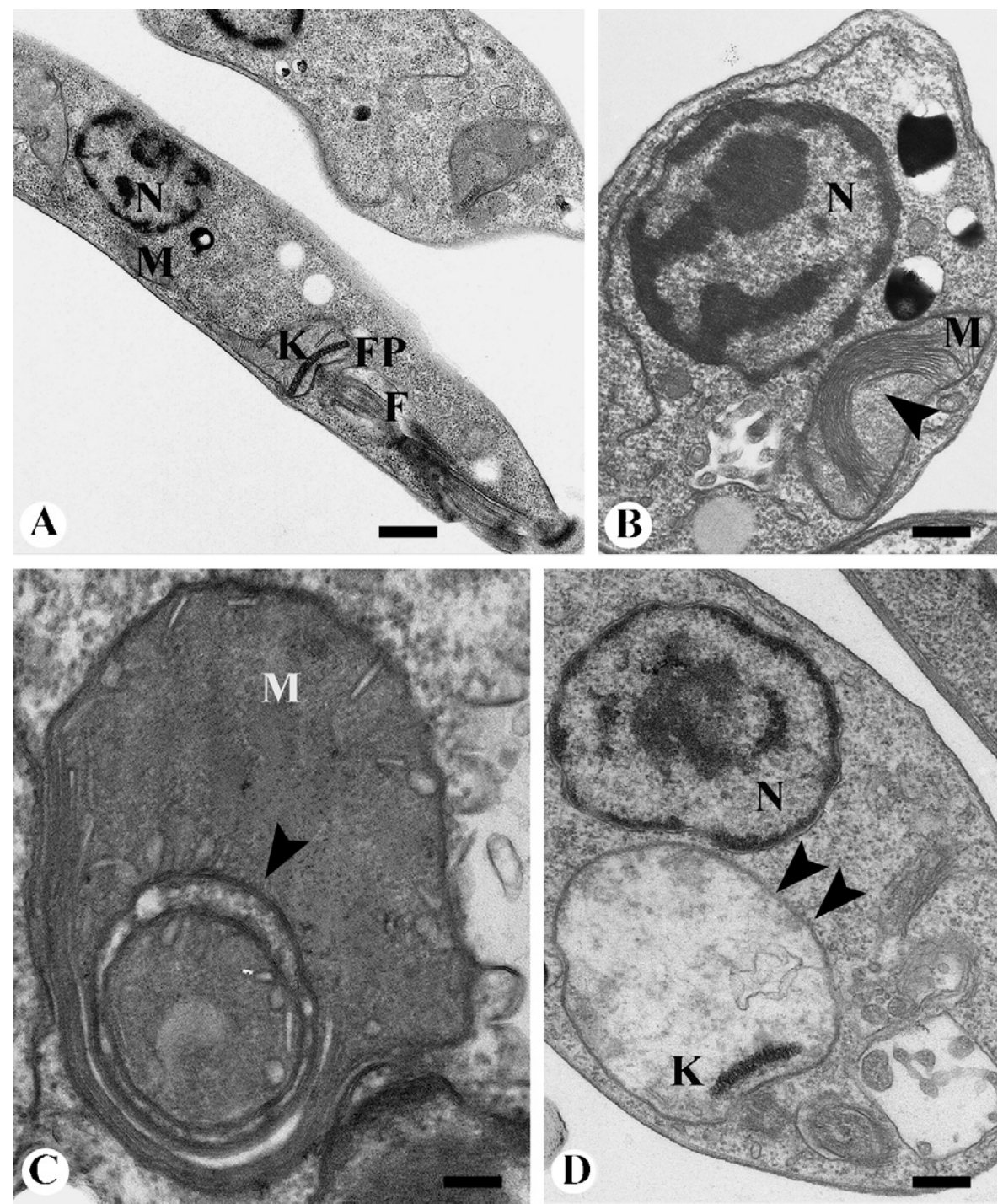

Fig. 6. Electron micrographs of promastigotes of Leishmania chagasi. (A) Control promastigote showing a normal morphology; (B-C) promastigotes of $L$. chagasi treated with $10 \mathrm{nM}$ of ER-119884 for $24 \mathrm{~h}$ (B) and for $48 \mathrm{~h}$ (C); (D) promastigotes of $L$. chagasi treated with $0.5 \mu \mathrm{M}$ of BPQ-OH (compound 1) for $96 \mathrm{~h}$. These figures show dramatic alterations in the mitochondrion morphology (arrowheads). N: nucleus; K: kinetoplast; M: mitochondrion; F: flagellum; FP: flagellar pocket.

We selected some of the most active compounds to analyze their effects on the parasite ultrastructure, as seen by TEM of thin sections. The following compounds were analyzed: 1, 2 and ER-119884. Control promastigotes (Fig. 6A) displayed an elongated cell body shaped by a layer of parallel subpellicular microtubules, the anterior long flagellum emerging from the flagellar pocket, a single branched mitochondrion containing the kinetoplast, as well as other structures such as vacuoles, lipid inclusions, acidocalcisomes, endoplasmic reticulum and the Golgi complex (reviewed in Vannier-Santos et al., 2002).
At all concentrations of the experimental compounds tested, significant morphological alterations were observed in the parasite structure. They varied from discrete changes to total destruction of the parasite. One important initial change was the swelling of the unique and highly branched mitochondrion, where the inner mitochondrial membrane lost its organization, displaying several and complex invaginations, forming concentric membranous structures (Figs. 6B-C and 7A, $\mathrm{C}-\mathrm{D})$. In addition, the matrix sometimes lost its characteristic electrondensity (Figs. 6D and 8B).

There was an increase in the number of autophagosomal structures, characterized by the profiles of the 

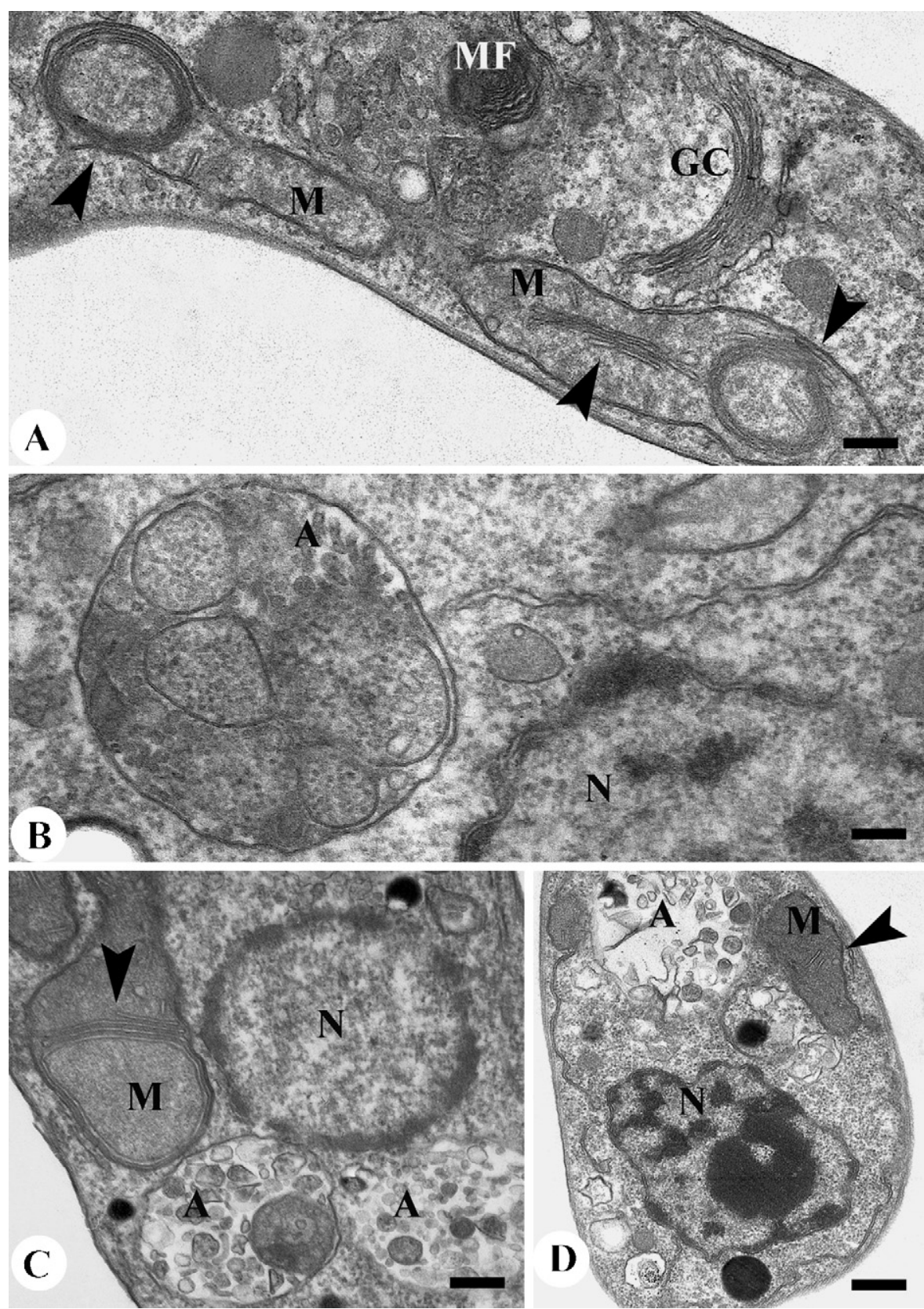

Fig. 7. Promastigotes of $L$. chagasi treated with BPQ-OH (compound 1), ER-119884 and compound 2. (A) Treatment with $0.5 \mu \mathrm{M}$ of BPQ-OH for $24 \mathrm{~h}$ showing the presence of myelin-like figures; (B) treatment with $0.5 \mu \mathrm{M}$ of BPQ-OH for $48 \mathrm{~h}$; (C) treatment with $10 \mathrm{nM}$ of ER-119884 for $72 \mathrm{~h}$; (D) treatment with $0.5 \mu \mathrm{M}$ of compound 2 for $96 \mathrm{~h}$. These figures show the presence of autophagosomes and disorganization in the inner mitochondrial membrane (arrowheads). N: nucleus; M: mitochondrion; A: autophagosome; MF: myelin-like figures; GC: Golgi complex.

endoplasmic reticulum surrounding various organelles forming multivesicular bodies (MVB) or by intense cytoplasmic vacuolization (Fig. 7B-D). We also observed the presence of myelin-like figures in drugtreated cells (Fig. 7A).

A third alteration frequently observed was the nuclear chromatin organization, resembling the nucleus of apoptotic cells (Figs. 6B and 7D). Alterations in the nuclear membrane were also observed (Fig. 7D).

The flagellum and flagellar pocket also showed alterations. Large amounts of membrane vesicles could be seen within the flagellar pocket of many treated cells (Fig. 8B). Portions of the membrane were detached 


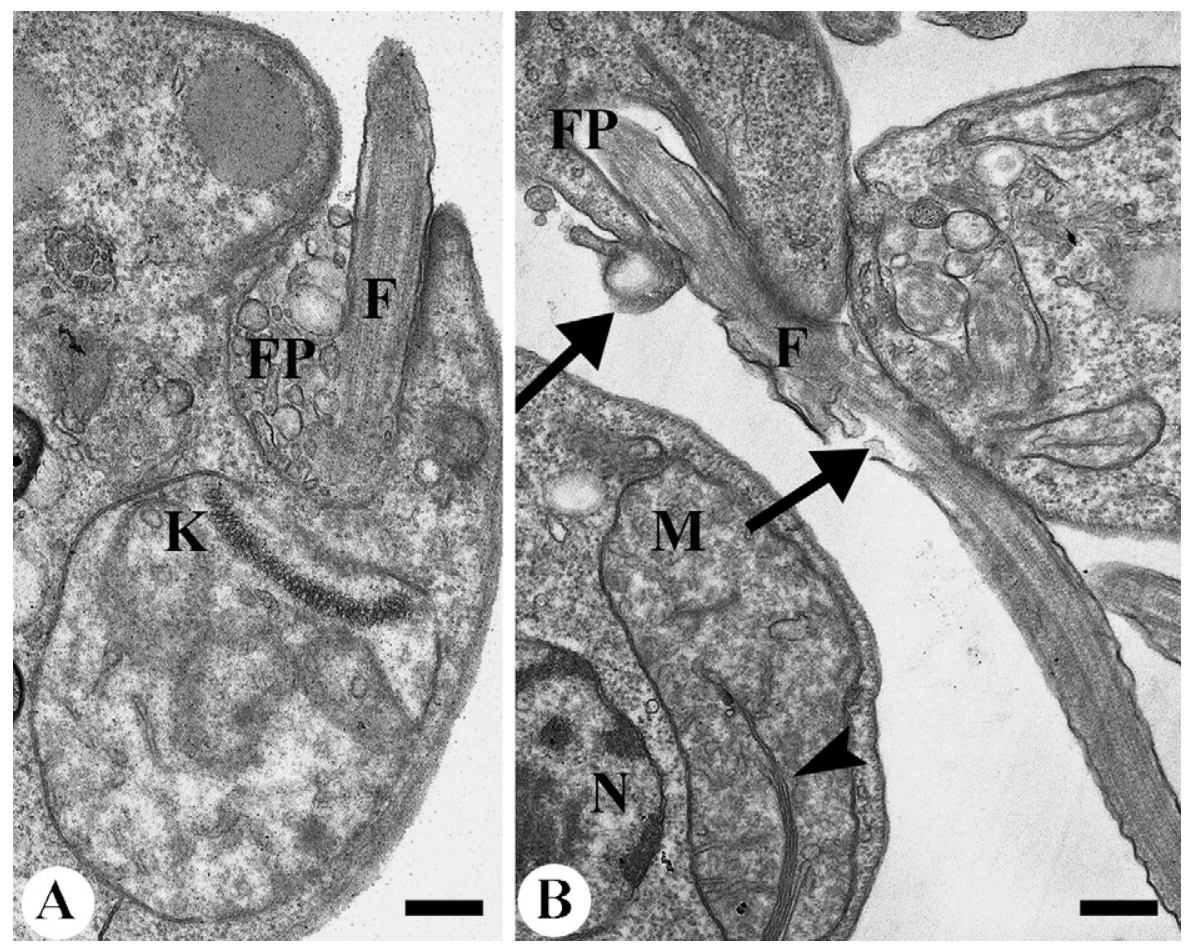

Fig. 8. Promastigotes of $L$. chagasi treated with $0.5 \mu \mathrm{M}$ of BPQ-OH (compound 1) (A-B). (A) Treatment for $24 \mathrm{~h}$ showing mitochondrial swelling and large amount of vesicles in the flagellar pocket; (B) treatment for $48 \mathrm{~h}$ showing the presence of some alterations in the flagellar membrane (arrows) and disorganization in the inner mitochondrial membrane (arrowheads). N: nucleus; K: kinetoplast; M: mitochondrion; F: flagellum; FP: flagellar pocket.

from the flagellum, sometimes forming a bleb, or seeming ruptured (Fig. 8A).

At $96 \mathrm{~h}$ of incubation with the drugs, a large number of parasites showed complete cell lysis (data not shown).

\section{Discussion}

Despite of the impressive advance of our knowledge on the biology of the etiological agents and the immunopathological aspects of the several forms of leishmaniasis, pentavalent antimonials, introduced empirically over 50 years ago, remain the first-line treatment for this infection in most endemic areas despite the limitations imposed by the need of parenteral administration, high toxicity and increasing drug resistance (Leandro and Campino, 2003; Melby, 2002; Murray, 2004). The most significant improvement on this situation has been the recent introduction of miltefosine as the first oral treatment for visceral leishmaniasis (Murray, 2004; Castro et al., 2004). Among other new approaches, treatment with $100 \mathrm{mg} / \mathrm{kg}$ terbinafine, a sterol biosynthesis inhibitors that acts at the level of squalene epoxidase, in L. chagasi-infected hamsters had no effect on spleen parasite burden (Simões-Mattos et al., 2002), while Dietze et al. (2001) treated human patients with WR6026, an orally bioavailable 8-aminoquinoline, and the drug was not efficacious. Nerolidol, an isoprenoid biosynthesis inhibitor, had a poor growth inhibitory action against $L$. amazonensis, $L$. brazilienses and $L$. chagasi promastigotes with an $\mathrm{IC}_{50}$ of 85,74 and $75 \mu \mathrm{M}$, respectively (Arruda et al., 2005).

In trypanosomatids, SQS is a membrane-bound enzyme, localized in glycosomes and mitochondria with possible presence in the endoplasmic reticulum (Urbina et al., 2002). Previous studies described the potent and selective effects of BPQ-OH and ER-27856, two specific SQS inhibitors, against Trypanosoma cruzi and Leishmania sp. (Urbina et al., 2002; Braga et al., 2004; Rodrigues et al., 2005; Lorente et al., 2005).

In the present study, we found that BPQ-OH (compound 1), was more active against $L$. chagasi than T. cruzi and Leishmania mexicana (Urbina et al., 2002; Braga et al., 2004). BPQ-OH analogs 2, 3, and 4 (Fig. 1) had an activity comparable to that of the parent compound, indicating that the elimination of the $3-\mathrm{OH}$ group, the introduction of a $\Delta^{2,3}$ double bond or the 
capping of the biphenyl group by a polar group had no significant effects on activity; these results contrast with those previously obtained against $L$. mexicana, where capping the biphenyl group with the bulky-OTBDMS moiety led to a almost complete loss of antiproliferative activity (Lorente et al., 2005). The presence of the rigid exocyclic double bond led to a reduction in activity (compounds 5-11). When this rigidity was removed, the activity increased (compounds 13 and 14). Interestingly, the naphthyl (13) and biphenyl (14) derivatives were more active than the phenyl analogue (12). Compound 15, which has the phenyl derivative held in a linear conformation by a triple bond, has only slightly lower activity than BPQ-OH. Swapping the ester (15) for an acid (16) led to a reduction in activity.

Taken together, these findings indicate that there is a strict requirement of a long, linear, hydrophobic moiety attached to the quinuclidine nucleus for antiproliferative activity, in agreement with previous studies on $L$. mexicana (Lorente et al., 2005 and Gibert, Urbina, in preparation). ER119884 and E5700 (Fig. 1), two arylpyridine quinuclidine derivatives in development as cholesterol-lowering agents by Eisai Company, were the most potent growth inhibitors on $L$. chagasi among the compounds tested, with growth inhibitory and leishmanicidal concentrations in the low nanomolar range (Table 1 and Figs. 2 and 5). Urbina et al. (2004) tested these compounds against $T$. cruzi, and observed that they were one order of magnitude more potent than BPQ-OH as inhibitors of the parasite enzyme (an activity enhanced in the presence of micromolar levels of inorganic pyrophosphate $\mathrm{PP}_{\mathrm{i}}$ ) and of the growth of both proliferative stages of the parasite. These authors did not observe deleterious effects caused by any of the compounds against host cell at concentrations up to 10-fold higher than the MIC (minimal concentration required to eradicate the intracellular amastigotes), indicating a selective antiparasitic effect. It has previously been shown, both in $T$. cruzi and in $L$. mexicana, that the antiproliferative effects of quinuclidine derivatives are strictly associated with the depletion of endogenous squalene and sterols, consistent with a blockade of de novo sterol biosynthesis at the level of SQS (Urbina et al., 2002, 2004; Lorente et al., 2005). Finally, the lower activity of the bisphosphonate pro-drug ER27856, when compared with the quinuclidines, is probably due to limited permeability through the membrane of the parasite.

Parasites treated with compounds 1, 2 and ER119884 were studied by TEM. Ultrastructural effects of these SQS inhibitors on the parasites were detected as early as $24 \mathrm{~h}$ after initiating the treatment. Most of the parasites presented remarkable swelling of the mitochondrion, and the internal mitochondrial membrane formed vesicles and concentric membrane structures. Lazardi et al. (1990) were the first authors to describe a marked alteration in the mitochondrion of T. cruzi as a consequence of ketoconazole-induced depletion of ergosterol. These alterations were also observed in T. cruzi (Braga et al., 2004) and L. amazonensis (Rodrigues et al., 2005) after treatment with different concentrations of BPQ-OH. Ketoconazole, terbinafine, 24(R,S),25-epiminolanosterol and 22,26-azasterol induce similar mitochondrial alterations in $T$. cruzi, L. amazonensis and Toxoplasma gondii (Vannier-Santos et al., 1995; Vivas et al., 1996; Rodrigues et al., 2002; Dantas-Leite et al., 2004). These results can suggest that the presence of ergosterol and analogues is essential for the maintenance of a normal structural organization, especially of the inner mitochondrial membrane in trypanosomatids. Biochemical studies have shown that the mitochondrial membrane of trypanosomatids is rich in endogenous and exogenous sterols, in contrast to mammalian cells where the mitochondrion is devoid of sterols (Haughan et al., 1995; Rodrigues et al., 2001).

The presence of autophagosomal structures was very prominent. Other authors also observed this alteration in T. cruzi and in L. amazonensis treated with different SBIs (Lazardi et al., 1990; Vannier-Santos et al., 1995; Rodrigues et al., 2002; Magaraci et al., 2003; Lorente et al., 2004). These structures are probably involved in the breakdown and recycling of abnormal membrane structures, suggesting an intense process of remodeling of intracellular organelles irreversibly damaged by the drug (Rodrigues et al., 2002).

The nuclear chromatin organization was altered, resembling apoptotic cells. Apoptosis is a programmed cell death process, which is characterized by a series of events involving morphological and biochemical changes. Apoptosis has been reported in a number of trypanosomatids (Debrabant et al., 2003). Novobiocin and camptothecin, topoisomerase inhibitors, induce apoptosis-like death in Leismania donovani (Sen et al., 2004; Singh et al., 2005). Further studies are necessary to better characterize the effect of these drugs in the nucleus.

Alterations in the flagellum membrane have been observed in T. cruzi treated with BPQ-OH (Braga et al., 2004). These authors suggested that changes in the chemical composition interfere in some way with the stability of the membranes, especially some domains lining the cell body and the flagellum. The appearance of various membranous structures within the flagellar pocket suggests an intense secretory process induced by 
the compounds. Several SBIs induced this effect in trypanosomatids including L. amazonensis (VannierSantos et al., 1995; Rodrigues et al., 2002; Braga et al., 2004).

In conclusion, our results indicate that SQS is a valid chemotherapeutic target in $L$. chagasi, and that quinuclidine derivatives are a promising chemotherapeutic approach for the treatment of infections caused by this parasite, both in man and dogs. These results warrant further studies in experimentally infected animal models.

\section{Acknowledgments}

We gratefully acknowledge the excellent technical assistance of Marlene Cazuza, Noêmia Gonçalves, Eliandro Lima and Antonio Bosco Carlos. This work was supported by the European Commission (Contract number ICA4-CT-2001-10074 to J.A.U., I.H.G. and W.S.), Programa de Núcleos de Excelência (PRONEX), Conselho Nacional de Desenvolvimento Científico e Tecnológico (CNPq), Coordenação de Aperfeiçoamento de Pessoal de Nível Suprior (CAPES) and Fundação Carlos Chagas Filho de Amparo à Pesquisa do Estado do Rio de Janeiro (FAPERJ).

\section{References}

Arruda, D.C., D’Alexandri, F.L., Katzin, A.M., Uliana, S.R.B., 2005. Antileishmanial activity of terpene nerolidol. Antimicrob. Agents Chemother. 49 (5), 1679-1687.

Barrett-Bee, K., Ryder, N.S., 1992. Biochemical aspects of ergosterol biosynthesis inhibitors. In: Sutcliffe, J., Georgopapadakou, N.H. (Eds.), Emerging Targets in Antibacterial and Antifungal Chemotherapy. Chapman and Hall, New York, pp. 410-436.

Bhattacharya, S.K., Jha, T.K., Sundar, S., Thakur, C.P., Engel, J., Sindermann, H., Junge, K., Karbwang, J., Bryceson, A.D.M., Berman, J.D., 2004. Efficacy and tolerability of miltefosine for childhood visceral leishmaniasis in India. Clin. Infect. Dis. 38, 217-221.

Braga, M.V., Urbina, J.A., De Souza, W., 2004. Effects of squalene synthase inhibitors on the growth and ultrastructure of Trypanosoma cruzi. Int. J. Antimicrob. Agents 24, 72-78.

Castro, S.L., Santa-Rita, R.M., Urbina, J.A., Croft, S.L., 2004. Antiprotozoal lysophospholipid analogues: a comparison of their activity against trypanosomatid parasites and tumor cells. Mini Rev. Med. Chem. 4, 139-148.

Contreras, L.M., Vivas, J., Urbina, J.A., 1997. Altered lipid composition and enzyme activities of plasma membranes from Trypanosoma (Schizotrypanum) cruzi epimastigotes grown in the presence of sterol biosynthesis inhibitors. Biochem. Pharmacol. 53, 697704.

Dantas-Leite, L., Urbina, J.A., de Souza, W., Vommaro, R.C., 2004. Selective anti-Toxoplasma gondii activities of azasterols. Int. J. Antimicrob. Agents 23, 620-626.
Debrabant, A., Lee, N., Bertholet, S., Duncan, R., Nakhasi, H.L., 2003. Programmed cell death in trypanosomatids and other unicellular organisms. Int. J. Parasitol. 33, 257-267.

Dietze, R., Carvalho, S.F.G., Valli, L.C., Berman, J., Brewer, T., Milhous, W., Sanchez, J., Schuster, B., Grogl, M., 2001. Phase 2 trial of WR6026, an orally administered 8-aminoquinoline, in the treatment of visceral leishmaniasis caused by Leishmania chagasi. Am. J. Trop. Med. Hyg. 65 (6), 685-689.

Ganguly, N.K., 2002. Oral miltefosine may revolutionize treatment of visceral leishmaniasis. The potential impact of miltefosine on visceral leishmaniasis in India. TDR News 68, 2.

Haughan, P.A., Chance, M.L., Goad, L.J., 1995. Effects of an azasterol inhibitor of sterol 24-transmethylation on sterol biosynthesis and growth of Leishmania donovani promastigotes. Biochem. J. 308, 31-38.

Kuhlencord, A., Maniera, T., Eibl, H., Unger, C., 1992. Hexadecylphosphocoline: oral treatment of visceral leishmaniasis in mice. Antimicrob. Agents Chemother. 36 (8), 1630-1634.

Lazardi, K., Urbina, J.A., de Souza, W., 1990. Ultrastructural alterations induced by two ergosterol biosynthesis inhibitors, ketoconazole and terbinafine, on epimastigotes and amastigotes of Trypanosoma (Schizotrypanum) cruzi. Antimicrob. Agents Chemother. 34, 2097-2105.

Leandro, C., Campino, L., 2003. Leishmaniasis: efflux pumps and chemoresistance. Int. J. Antimicrob. Agents 22, 352-357.

Lira, R., Contreras, L.M., Santa-Rita, R.M., Urbina, J.A., 2001. Mechanism of action of anti-proliferative lysophospholipid analogues against the protozoan parasite Trypanosoma cruzi: potentiation of in vitro activity by the sterol biosynthesis inhibitor ketoconazole. J. Antimicrob. Chemother. 47, 537546.

Lorente, S.O., Rodrigues, J.C.F., Jimenez, C.J., Joyce-Menekse, M., Rodriguez, C., Croft, S.L., Yardley, V., de Luca-Fraley, K., RuizPerez, L.M., Urbina, J.A., de Souza, W., Pacanowska, D.G., Gilbert, I.H., 2004. Novel azasterols as potential agents for treatment of leishmaniasis and trypanosomiasis. Antimicrob. Agents Chemother. 48, 2937-2950.

Lorente, S.O., Gomez, R., Jimenez, C.J., Cammerer, S., Yardley, V., de Luca-Fradley, K., Croft, S.L., Perez, R., Urbina, J.A., Pacanowska, D.G., Gilbert, I.H., 2005. Biphenylquinuclidines as inhibitors of squalene synthase and growth of parasitic protozoa. Bioorg. Med. Chem. 13, 3519-3529.

Magaraci, F., Jimenez, C.J., Rodriguez, C., Rodrigues, J.C.F., Braga, M.V., Yardley, V., de Luca-Fradley, K., Croft, S.L., de Souza, W., Ruiz-Perez, L.M., Urbina, J.A., Pacanowska, D.G., Gilbert, I.H., 2003. Azasterols as inhibitors of sterol 24-methyltransferase in Leishmania species and Trypanosoma cruzi. J. Med. Chem. 46, 4714-4727.

Martin, M.B., Grimley, J.S., Lewis, J.C., Heath, H.T., Bailey, B.N., Kendrick, H., Yardley, V., Caldera, A., Lira, R., Urbina, J.A., Moreno, S.N.J., Docampo, R., Croft, S.L., Oldfield, E., 2001. Bisphosphonates inhibit the growth of Trypanosoma brucei, Trypanosoma cruzi, Leishmania donovani, Toxoplasma gondii, and Plasmodium falciparum: a potential route to chemotherapy. J. Med. Chem. 44, 909-916.

Melby, P.C., 2002. Recent developments in leishmaniasis. Curr. Opin. Infect. Dis. 15, 485-490.

Molina, R., Amela, C., Nieto, J., San-Andres, M., Gonzalez, F., Castillo, J.A., Lucientes, J., Alvar, J., 1994. Infectivity of dogs naturally infected with Leishmania infantum to colonized Phlebotomus perniciosus. Trans. R. Soc. Trop. Med. Hyg. 88, 491-493. 
Murray, H.W., 2004. Progress in the treatment of a neglected infectious disease: visceral leishmaniasis. Expert Rev. Anti Infect. Ther. 2, 279-292.

Oehlschlager, A.C., Czyzewska, E., 1992. Rationally designed inhibitors of sterol biosynthesis. In: Sutcliffe, J., Georgopapadakou, N.H. (Eds.), Emerging Targets in Antibacterial and Antifungal Chemotherapy. Chapman and Hall, New York, pp. 410-436.

Rakotomanga, M., Loiseau, P.M., Saint-Pierre-Chazalet, M., 2004. Hexadecylphosphocholine interaction with lipid monolayers. Biochim. Biophys. Acta 1661, 212-218.

Roberts, C.W., McLeod, R., Rice, D.W., Ginger, M., Chance, M.L., Goad, L.J., 2003. Fatty acid and sterol metabolism: potential antimicrobial targets in apicomplexan and trypanosomatid parasitic protozoa. Mol. Biochem. Parasitol. 126, 129-142.

Rodrigues, C.O., Catisti, R., Uyemura, S.A., Vercesi, A.E., Lira, R., Rodriguez, C., Urbina, J.A., Docampo, R., 2001. The sterol composition of Trypanosoma cruzi changes after growth in different culture media and results in different sensitivity to digitonin-permeabilization. J. Eukaryot. Microbiol. 48, 588-594.

Rodrigues, J.C.F., Attias, M., Rodriguez, C., Urbina, J.A., de Souza, W., 2002. Ultrastructural and biochemical alterations induced by 22,26-azasterol, a $\Delta^{24(25)}$-sterol methyltransferase inhibitor, on promastigote and amastigote forms of Leishmania amazonensis. Antimicrob. Agents Chemother. 46, 487-499.

Rodrigues, J.C.F., Urbina, J.A., de Souza, W., 2005. Antiproliferative and ultrastructural effects of BPQ-OH, a specific inhibitor of squalene synthase, on Leishmania amazonensis. Exp. Parasitol. 111, 230-238.

Rosenthal, E., Marty, P., 2003. Recent understanding in the treatment of visceral leishmaniasis. J. Postgrad. Med. 49, 61-68.

Sen, N., Das, B.B., Ganguly, A., Mukherjee, T., Tripathi, G., Bandyopadhyay, S., Rakshit, S., Sen, T., Majumder, H.K., 2004. Camptothecin induced mitochondrial dysfunction leading to programmed cell death in unicellular hemoflagellate Leishmania donovani. Cell Death Differ. 11 (8), 924-936.

Simões-Mattos, L., Teixeira, M.J., Costa, D.C., Prata Jr., J.R.C., Bevilaqua, C.M.L., Sidrim, J.J.C., Rocha, M.F.G., 2002. Evaluation of terbinafine treatment in Leishmania chagasi-infected hamsters (Mesocricetus auratus). Vet. Parasitol. 103, 207-216.
Sinderman, H., Croft, S.K., Engel, K.R., Bommer, W., Eibl, H.J., Unger, C., Engel, J., 2004. Miltefosine (Impavido ${ }^{\circledR}$ ): the first oral treatment against leishmaniasis. Med. Microbiol. Immunol. 193, 173-180.

Singh, G., Jayanarayan, K.G., Dey, C.S., 2005. Novobiocin induces apoptosis-like cell death in topoisomerase II over-expressing arsenite resistant Leishmania donovani. Mol. Biochem. Parasitol. 141, 57-69.

Sundar, S., 2001. Drug resistance in Indian visceral leishmaniasis. Trop. Med. Int. Health 6 (2), 849-854.

Urbina, J.A., 2006. Mechanisms of action of lysophospholipid analogues against trypanosomatid parasites. Trans. R. Soc. Trop. Med. Hyg. 100 (1), 9-16.

Urbina, J.A., 1997. Lipid biosynthesis pathways as chemotherapeutic targets in kinetoplastid parasites. Parasitology 114 (Suppl.), S91S99.

Urbina, J.A., 1999. Chemotherapy of Chagas' disease: the how and the why. J. Mol. Med. 77, 332-338.

Urbina, J.A., Concepcion, J.L., Caldera, A., Payares, G., Sanoja, C., Otomo, T., Hiyoshi, H., 2004. In vitro and in vivo activities of E5700 and ER-119884, two novel orally active squalene synthase inhibitors, against Trypanosoma cruzi. Antimicrob. Agents Chemother. 48 (7), 2379-2387.

Urbina, J.A., Concepcion, J.L., Rangel, S., Visbal, G., Lira, R., 2002. Squalene synthase as a chemotherapeutic target in Trypanosoma cruzi and Leishmania mexicana. Mol. Biochem. Parasitol. 125, $35-45$.

Vannier-Santos, M.A., Martiny, A., de Souza, W., 2002. Cell biology of Leishmania spp.: invading and evading. Curr. Pharm. Des. 8, 297-318.

Vannier-Santos, M.A., Urbina, J.A., Martiny, A., Neves, A., de Souza, W., 1995. Alterations induced by the antifungal compounds ketoconazole and terbinafine in Leishmania. J. Eukaryot. Microbiol. 42, 337-346.

Vivas, J., Urbina, J.A., de Souza, W., 1996. Ultrastructural alterations in Trypanosoma (Schizotrypanum) cruzi induced by a $\Delta^{24(25)}$ sterol methyltransferase inhibitors and their combinations with ketoconazole. Int. J. Antimicrob. Agents 7, 235-240.

WHO, 2002. Epidemiological Bulletin/PAHO, vol. 23, No. 3. 